\title{
Caracterización Fisicoquímica, Bromatológica y Microbiológica de Bebidas Autóctonas de Córdoba, Colombia
}

\author{
Yenis I. Pastrana ${ }^{(1) *}$, Alba M. Durango ${ }^{(1)}$ Claudia D. de Paula ${ }^{(1) \star}$ y Diofanor Acevedo ${ }^{(2)}$ \\ (1) Univ. de Córdoba, Facultad de Ingeniería, Departamento de Ingeniería de Alimentos, Km 12 vía Cereté - \\ Ciénaga de Oro, Sede de Berástegui, Córdoba-Colombia (e-mail: yipastrana@correo.unicordoba.edu.co) \\ (2) Universidad de Cartagena, Facultad de Ingeniería, Programa de Ingeniería de Alimentos, Avenida el \\ Consulado, Calle 30 No. 48-152. Cartagena, Bolívar-Colombia
}

* Autor a quien debe ser dirigida la correspondencia

Recibido Sep. 11, 2014; Aceptado Nov. 11, 2014; Versión final Ene. 17, 2015, Publicado Ago. 2015

\section{Resumen}

Se ha realizado la caracterización bromatológica, fisicoquímica y microbiológica de Avena Sinuana y de Chicheme, bebida autóctonas de Córdoba en Colombia. Se realizaron visitas a seis proveedores, se observaron los procesos productivos y se tomaron muestras al azar. Los análisis se realizaron por triplicado durante tres días, siguiendo los métodos oficiales de Química Analítica, y las Normas Técnicas Colombianas de microbiología. Se realizaron análisis de varianza y comparaciones múltiples $(p \leq 0,05)$. La Avena Sinuana presentó mayores porcentajes de cenizas (1.39), azúcares totales (5.03) y azúcares reductores (5.51). El Chicheme destacó por el contenido de proteínas (6.77). grasa (1.02) y acidez (0.39). Los recuentos microbianos sobrepasaron los límites establecidos: en la Avena Sinuana los más altos fueron mesófilos (3.59) y coliformes totales (3.38); en el Chicheme los más altos fueron mesófilos (4.21) y coliformes fecales (3.28). Esto reveló que estas son bebidas con una cantidad adecuada de nutrientes, pero elaboradas con deficientes condiciones sanitarias.

Palabras clave: bebidas autóctonas, avena sinuana, chicheme, análisis microbiológico, control sanitario

\section{Physicochemical, Bromatological and Microbiological Characterization of local drinks from Cordoba, Colombia}

\begin{abstract}
Bromatological, physicochemical and microbiological characterization of Oats Sinuana and Chicheme, local drinks made in Cordoba, Colombia, were performed. Visits were done to six vendors, their production processes were observed and several random samples were taken. Analyses were performed in triplicate during three days, following the methodology of the International Association of Analytical Chemistry and of the Colombian Technical Standards on microbiology. Analysis of variance and multiple comparisons ( $p \leq$ $0.05)$ were performed. Oats Sinuana had higher percentages of ash (1.39) for total sugars (5.03) and reducing sugars (5.51). The Chicheme presented high content of protein (6.77), fat (1.02) and acidity (0.39). The microbial counts exceeded the limits: for Avena Sinuana the highest were mesophilic (3.59) and total coliforms (3.38); for Chicheme the highest content were mesophilic (4.21) and fecal coliforms (3.28). This revealed that these drinks have adequate amount of nutrients but are elaborated under deficient sanitary conditions.
\end{abstract}

Keywords: local drinks, avena sinuana, chicheme, microbiological analysis, sanitary control 


\section{INTRODUCCIÓN}

Los alimentos artesanales son reconocidos por su lugar de procedencia y elaboración tradicional, han sido estudiados por sus características y potencialidades (Blanco et al., 2014; Becerra, 2014). Actualmente, no se cuenta con un concepto unificado de lo que se entiende por artesanal, ya que varía de acuerdo a las personas, regiones y países; aunque se tienen disponibles algunas definiciones que hacen referencia a productos comestibles hechos a mano, no toman en consideración la existencia de las normatividades actuales (Domínguez-López et al., 2011). Quintero-Salazar et al., (2012) señalan que en general, los alimentos tradicionales están asociados a un territorio y cultura específica. Pazmiño et al., (2014) afirman que todos los productos típicos se elaboran por medio de procesos empíricos propios del desarrollo espontáneo transmitido mediante tradición oral.

Los productos artesanales y tradicionales han incrementado recientemente su popularidad y su producción, se han propuesto como una importante alternativa de innovación a los actuales sistemas agroalimentarios locales, de países con economías emergentes donde predominan las microempresas, ya que posibilitaría rescatar las tradiciones y agregar valor a los productos típicos más apetecidos por los consumidores, lo que facilitaría el desarrollo de la agroindustria artesanal y mejoraría los ingresos de los pequeños productores rurales (López-Arboleda et al., 2010; Domínguez et al., 2011).

Actualmente, los productos autóctonos son considerados exóticos por sus ingredientes y las técnicas especiales de producción; para hacerlos competitivos, se debe prolongar la vida útil de los mismos, desarrollando nuevos métodos de conservación que impliquen cambios en su procesamiento, pero sin alterarlos en su esencia, permitiendo potencializar sus características y aumentar su comercialización en los mercados más exigentes (Arzeno y Troncoso, 2012). Para lograr esto, es necesario conocer profundamente su composición (García y Pacheco, 2010; Muñiz-Márquez et al., 2013). Montoya et al., (2014) indica que para proteger la salud de los consumidores, es una necesidad que los alimentos artesanales y tradicionales cumplan con requisitos mínimos en cuanto a los parámetros fisicoquímicas y microbiológicas.

El cultivo y consumo de avena (Avena Sativa L.) es multipropósito y ha crecido en todo el mundo durante las últimas décadas. Esta es rica en proteínas de alto valor biológico, grasas y un gran número de vitaminas y minerales (Luana et al., 2014). Es el cereal con mayor proporción de grasa vegetal, un $65 \%$ no saturada y un $35 \%$ de ácido linolénico (Pagés et al., 2013). También contiene hidratos de carbono de fácil absorción, además de calcio, cinc, cobre, fósforo, hierro, magnesio, potasio, sodio; vitaminas B1, B2, B3, B6 y E. A su vez posee una buena cantidad de fibras, que contribuyen al buen funcionamiento intestinal (Muñoz-Insa et al., 2011). La avena ha sido utilizada para el desarrollo de bebidas fermentadas, o en forma tradicional con leche, agua y especias al gusto (Gupta et al., 2010; Pagés et al., 2013).

La Norma Técnica Colombiana (NTC) 5246, (2004) establece que: "bebida láctea con avena, es la obtenida mediante proceso térmico de pasteurización, ultrapasteurización, (UHT) ultra alta temperatura, aplicado a una mezcla de leche, leche en polvo, agua, avena, edulcorantes y saborizantes naturales o artificiales y estabilizantes". Así mismo, también define las bebidas lácteas con avena pasteurizada como: "una mezcla de leche, leche en polvo, agua, avena, edulcorantes y saborizantes naturales o artificiales y estabilizantes, sometida a una adecuada relación de tiempo y temperatura para destruir la flora patógena y casi la totalidad de su flora banal, sin alterar de manera esencial ni su valor nutritivo, ni sus características fisicoquímicas y organolépticas". Señala también que las condiciones mínimas de pasteurización son aquellas que tienen efectos bactericidas equivalentes al calentamiento de cada partícula a $72{ }^{\circ} \mathrm{C}$ por $15 \mathrm{~s}$ (pasteurización de flujo continuo) o a $63^{\circ} \mathrm{C}$ por 30 min (pasteurización discontinua).

La gastronomía del Departamento de Córdoba (Colombia) se encuentra influenciado por una diversa variedad de alimentos típicos muy apetecidos por los consumidores (tanto a nivel regional como nacional), debido a su sabor y aroma; donde se mezclan materias primas nativas e ingredientes foráneos (Pastrana, 2013). Una de las bebidas típicas, es la llamada Avena Sinuana, que cabe dentro de la definición de "bebidas lácteas con avena pasteurizada (discontinuamente)", entre las recomendaciones se indica que debe tener como mínimo $50 \% \mathrm{v} / \mathrm{v}$ de leche fluida y $3 \%$ de $\mathrm{p} / \mathrm{v}$ de avena (hojuela, molida o en grano (Pastrana, 2013). Así mismo se produce en dicho departamento otra importante las bebida, a partir de granos de maíz de las variedades amarilla, blanca, o roja, comúnmente llamada Chicha o Chicheme, que se puede definir según la norma como "bebida con adición de leche", lo cual hace referencia al producto obtenido al someter la leche cruda con la mezcla de otros ingredientes en una proporción mínima del 40\%(p/v) (López-Arboleda et al., 2010; Pastrana, 2013). Estas bebidas, ocupan un renglón importante en la economía micro-empresarial de numerosas familias Cordobesas. El establecer sus características intrínsecas, posibilitará desarrollar productos innovadores que se puedan llevar a otro nivel en el mercado de consumo. Por ello el objetivo de esta investigación fue caracterizar las propiedades bromatológicas, fisicoquímicas y microbiológicas de la Avena Sinuana y el Chicheme elaborados en los municipios de Cereté y Cienaga de Oro del Departamento de Córdoba - Colombia. 


\section{MATERIALES Y MÉTODOS}

La población objeto de estudio que se utilizó para la investigación fueron las bebidas autóctonas Avena Sinuana y Chicheme, elaboradas en los municipios de Cereté y Ciénaga de Oro respectivamente, ubicados en el Departamento de Córdoba (Colombia). Se diseñó un formato para recolectar toda la información relacionada con los insumos utilizados en la preparación de las bebidas. Se efectuó un censo de las microempresas existentes en los municipios. Se realizaron visitas a seis famiempresas donde elaboraron y comercializaron estos productos y se tomaron muestras completamente al azar, después de observar los procesos productivos. Los análisis bromatológicos, fisicoquímicos, microbiológicos se realizaron en las instalaciones del programa Ingeniería de Alimentos de la Universidad de Córdoba.

\section{Descripción del proceso en las famiempresas del municipio de Cereté}

Los ingredientes que se utilizaron para la elaboración del producto fueron: agua, leche en polvo, avena molida, azúcar, sal, y especias como el clavo y la canela, en las mismas proporciones en las tres famiempresas. Se presentaron variaciones en las operaciones de preparación, pues aunque fueron las mismas, la duración y el orden variaron ligeramente. En el proceso, en primer lugar, se midió la cantidad de agua a utilizar como base de cálculo, posteriormente se licuó el agua en conjunto con la avena molida y la leche, seguido de esto, se le adicionó clavo y la canela. Esta mezcla se llevó a cocción por ebullición a una temperatura de $90^{\circ} \mathrm{C}$ durante 30 minutos, donde se le adicionó el azúcar, la sal y se continuó el proceso térmico con agitación constante, para evitar la adherencia en la paredes del recipiente utilizado, el cual fue una vasija rectangular de metal de aproximadamente diez litros de capacidad y resistente a las condiciones del proceso. Posteriormente cuando el producto alcanzó la cocción adecuada, fue vertido en otra vasija y sometido a enfriamiento al sumergirse dicho recipiente en otro más grande con agua, a una temperatura entre 20 y $25^{\circ} \mathrm{C}$. Inmediatamente se envasó en caliente en botellas de vidrios de $250 \mathrm{~mL}$ de capacidad, que se almacenaron primeramente a temperatura ambiente y después en refrigeradores a $4^{\circ} \mathrm{C}$. Para su posterior comercialización. En la Tabla 1, se resumen los insumos y cantidades utilizadas para la preparación de la Avena Sinuana.

Tabla 1: Formulación utilizada en las famiempresas para la elaboración de la Avena Sinuana

\begin{tabular}{|c|c|c|c|c|c|c|}
\hline Insumos & Agua & Leche en polvo & Avena molida & Azúcar & Clavo y Canela & Sal \\
\hline Porcentaje $(\% \mathrm{p} / \mathrm{v})$ & 79,29 & 11 & 4 & 8,5 & 0,20 & 0,01 \\
\hline
\end{tabular}

\section{Descripción del proceso en las famiempresas del municipio de Ciénaga de Oro}

En los tres famiempresas visitados, se observaron las mismas materias primas, variando una de ellas que utilizó solo canela, mientras las otras dos, emplearon ambas especias (clavo y canela). Las operaciones cambiaron de orden o intensidad dependiendo de los fabricantes. En la Tabla 2, se muestra la formulación para la preparación del Chicheme. En primer lugar, se calculó la cantidad de agua, inmediatamente se procedió a pesar cada ingrediente. Seguido de esto, se adicionó una mezcla de clavo y canela, y llevó el producto a cocción por ebullición, en una vasija de metal de quince litros de capacidad. Mientras se agitó se le adicionó el maíz cocido de la variedad blanca, según la preferencia de los consumidores del municipio. Posteriormente cuando el producto llegó a una etapa de cocción, fue retirado y se licuó la mezcla en caliente con la leche en polvo y se le adicionó la sal. Inmediatamente, se llevó a una segunda cocción con agitación constante para evitar su adherencia en las paredes del recipiente. Finalmente se sometió a enfriamiento en otro recipiente de metal lleno de agua a una temperatura entre 20 y $25^{\circ} \mathrm{C}$. Se le adicionó hielo y fue dosificado en vasos de plástico sellados para su posterior distribución.

Tabla 2: Formulación utilizada en las famiempresas para la elaboración del Chicheme

\begin{tabular}{|c|c|c|c|c|c|c|}
\hline Insumo & Agua & Leche en polvo & Maíz trillado & Azúcar & Clavo y Canela & Sal \\
\hline Porcentaje $(\% \mathrm{p} / \mathrm{v})$ & 61,84 & 11 & 15 & 12 & 0,15 & 0,01 \\
\hline
\end{tabular}

\section{Caracterización de las muestras de Avena Sinuana y Chicheme}

Los ensayos fisicoquímicos realizados fueron: $\mathrm{pH}$ mediante método potenciométrico según A.O.A.C. 981.12/90; 'Brix por método refractométrico según A.O.A.C. 932.12/90; azúcares reductores según método Miller G.L. DNS (Miller, 1959); azúcares totales por método fenol sulfúrico (Dubois et al., 1956) y acidez por titulación según A.O.A.C. 942.15/90 adaptado. Los ensayos bromatológicos fueron: humedad, mediante secado por estufa según A.O.A.C. 930.15/90; cenizas con secado por mufla según A.O.A.C. 942.05/90; proteína total mediante método Macro Kjeldahl según A.O.A.C. 955.45/90 y grasa mediante equipo Soxhlet 
según la Norma Técnica Colombiana (NTC) 4722 de 1999. A las bebidas típicas se les realizaron análisis microbiológicos de: mesófilos aerobios, bacterias ácido lácticas (BAL), Coliformes totales y fecales, y Staphylococcus aureus coagulasa positiva, de acuerdo a la metodología propuesta por las Normas Técnicas Colombianas, NTC 2160 (2006), NTC 4458 (2007) y NTC 4779 (2007). Estos análisis se realizaron durante tres días consecutivos a los productos de las famiempresas seleccionadas.

\section{Análisis de datos}

En la investigación, se manejó un diseño experimental completamente aleatorizado (DCA). Los análisis en los laboratorios bajo condiciones controladas de temperatura y humedad ambiente, se efectuaron por triplicado y los resultados expresados como la media con su desviación estándar. Se utilizó el Programa Estadístico para Ciencias, IBM SPSS Statistics Inc. (C) - versión 19.0 en Windows, para realizar los análisis de varianza (ANOVA) y para la comparación de medias se empleó el test de HSD Tukey, con nivel de significancia al $5 \%(p \leq 0,05)$.

\section{RESULTADOS Y ANÁLISIS}

\section{Caracterización bromatológica y fisicoquímica de la Avena Sinuana y del Chicheme}

En la Tabla 3, se muestran los datos obtenidos de la caracterización bromatológica y fisicoquímica de la Avena Sinuana. Los datos representan el promedio de los tres días en cada proveedor. Se observa que entre proveedores no hubo diferencias estadísticamente significativas en cuanto a los contenidos de humedad, cenizas, proteínas, grasa, azúcares reductores, azúcares totales y grados Brix $(p>0,05)$. Mientras que en los contenidos totales de acidez, si se observaron diferencias $(p<0,05)$, especialmente en la muestra del proveedor 2 , cuyo contenido fue el más elevado $0,21 \pm 0,01 \%$. Lo cual puede ser atribuido al contenido de ácido láctico en este producto, lo que se reflejó en los valores de $\mathrm{pH}$ en esta muestra, que fueron los más bajos. Estos valores de pH fueron similares a los encontrados por Rojas, (2012) en su trabajo, desarrollo y caracterización de una nueva bebida de avena, donde obtuvo un promedio de 6,58.

Tabla 3: Caracterización bromatológica y fisicoquímica de la Avena Sinuana entre los proveedores

\begin{tabular}{|c|c|c|c|c|c|c|c|}
\hline \multicolumn{4}{|c|}{ Avena Sinuana } & \multicolumn{4}{c|}{ Análisis de Varianza } \\
\hline Parámetros/Proveedores & Proveedor 1 & Proveedor 2 & Proveedor 3 & $\begin{array}{c}\text { Suma de } \\
\text { Cuadrados }\end{array}$ & $\begin{array}{c}\text { Media } \\
\text { cuadrática }\end{array}$ & Valor F & $p$-valor \\
\hline$\%$ Humedad & $84,58 \pm 7,26 \mathrm{a}$ & $80,04 \pm 3,37 \mathrm{a}$ & $80,33 \pm 0,53 \mathrm{a}$ & 104,05 & 52,03 & 0,77 & 0,52 \\
\hline$\%$ Cenizas (BS) & $1,21 \pm 0,63 \mathrm{a}$ & $1,55 \pm 0,27 \mathrm{a}$ & $1,42 \pm 0,50 \mathrm{a}$ & 0,19 & 0,12 & 0,45 & 0,67 \\
\hline$\%$ Proteína & $4,51 \pm 0,90 \mathrm{a}$ & $5,78 \pm 1,73 \mathrm{a}$ & $5,85 \pm 0,61 \mathrm{a}$ & 5,41 & 2,71 & 1,84 & 0,27 \\
\hline$\%$ Grasa (BS) & $0,79 \pm 0,06 \mathrm{a}$ & $1,34 \pm 0,39 \mathrm{a}$ & $0,67 \pm 0,58 \mathrm{a}$ & 0,75 & 0,37 & 1,56 & 0,32 \\
\hline$\%$ Azúcares Totales & $4,06 \pm 0,78 \mathrm{a}$ & $5,21 \pm 0,22 \mathrm{~b}$ & $5,83 \pm 0,38 \mathrm{~b}$ & 2,35 & 1,18 & 9,74 & 0,03 \\
\hline$\%$ Azúcares Reductores & $4,85 \pm 1,36 \mathrm{a}$ & $5,76 \pm 2,01 \mathrm{a}$ & $5,91 \pm 1,11 \mathrm{a}$ & 8,95 & 4,47 & 4,11 & 0,11 \\
\hline oBrix & $14,59 \pm 1,20 \mathrm{a}$ & $14,17 \pm 0,76 \mathrm{a}$ & $14,33 \pm 0,15 \mathrm{a}$ & 0,27 & 0,14 & 0,32 & 0,74 \\
\hline$\%$ Acidez (Ac. Láctico) & $0,09 \pm 0,01 \mathrm{a}$ & $0,21 \pm 0,01 \mathrm{~b}$ & $0,07 \pm 0,01 \mathrm{a}$ & 0,02 & 0,00 & 60,52 & 0,00 \\
\hline pH & $4,92 \pm 0,05 \mathrm{a}$ & $4,88 \pm 0,02 \mathrm{a}$ & $6,58 \pm 0,02 \mathrm{~b}$ & 5,64 & 2,82 & 10,66 & 0,00 \\
\hline
\end{tabular}

Con respecto a la materia grasa, la muestra del proveedor 2 , fue la que cumplió con estos valores mínimos $(1,34 \%)$, mientras que los otros proveedores no alcanzaron lo estipulado de $1,0 \%$. En cuanto a los porcentajes de azúcares reductores, se observaron algunas diferencias entre proveedores, pero que no fueron estadísticamente significativas $(p<0,05)$. Mientras que para los azúcares totales, fueron las muestras del proveedor 1 , las de menor contenido $(p<0,05)$. Estas variaciones pueden ser atribuidas a la falta de estandarización observada en la elaboración de este producto en las famiempresas artesanales del municipio de Cereté-Córdoba.

En la Tabla 4, se esquematizan los valores promedios de la caracterización bromatológica y fisicoquímica del Chicheme, representan el promedio de los tres días para cada proveedor. Se observa que no hubo diferencias estadísticas en los porcentajes de humedad, proteínas, azúcares totales, azúcares reductores, @Brix y ácido láctico $(p>0,05)$ de los tres proveedores. Al analizar las cantidades de cenizas, se encontró que el proveedor 1 , presentó los valores más altos $(p<0,05)$. En cuanto a la grasa también se encontraron diferencias $(p<0,05)$, siendo la de mayor porcentaje la muestra del proveedor 3 , la cual fue la única que cumplió con lo establecido en las normas. 
Tabla 4: Caracterización bromatológica y fisicoquímica del Chicheme entre los proveedores

\begin{tabular}{|c|c|c|c|c|c|c|c|}
\hline \multicolumn{4}{|c|}{ Chicheme } & \multicolumn{4}{c|}{ Análisis de Varianza } \\
\hline Parámetros/Descriptivos & Proveedor 1 & Proveedor 2 & Proveedor 3 & $\begin{array}{c}\text { Suma de } \\
\text { Cuadrados }\end{array}$ & $\begin{array}{c}\text { Media } \\
\text { cuadrática }\end{array}$ & Valor $F$ & $p$-valor \\
\hline$\%$ Humedad & $83,39 \pm 2,45 \mathrm{a}$ & $83,45 \pm 2,15 \mathrm{a}$ & $82,91 \pm 3,07 \mathrm{a}$ & 5,14 & 2,57 & 0,34 & 0,73 \\
\hline$\%$ Cenizas (BS) & $1,08 \pm 0,02 \mathrm{a}$ & $0,91 \pm 0,04 \mathrm{~b}$ & $0,82 \pm 0,13 \mathrm{~b}$ & 0,05 & 0,03 & 7,79 & 0,04 \\
\hline$\%$ Proteína & $6,19 \pm 1,31 \mathrm{a}$ & $7,46 \pm 0,54 \mathrm{a}$ & $6,65 \pm 0,67 \mathrm{a}$ & 2,49 & 1,25 & 1,94 & 0,26 \\
\hline \% Grasa (BS) & $0,90 \pm 0,05 \mathrm{a}$ & $0,77 \pm 0,23 \mathrm{a}$ & $1,38 \pm 0,17 \mathrm{~b}$ & 0,62 & 0,31 & 7,78 & 0,04 \\
\hline$\%$ Azúcares Totales & $4,16 \pm 0,31 \mathrm{a}$ & $3,68 \pm 0,11 \mathrm{a}$ & $4,22 \pm 0,76 \mathrm{a}$ & 5,74 & 2,87 & 6,20 & 0,08 \\
\hline$\%$ Azúcares Reductores & $4,28 \pm 0,49 \mathrm{a}$ & $3,78 \pm 0,55 \mathrm{a}$ & $3,98 \pm 0,93 \mathrm{a}$ & 3,68 & 1,84 & 0,86 & 0,49 \\
\hline oBrix & $15,06 \pm 0,13 \mathrm{a}$ & $15,93 \pm 0,21 \mathrm{a}$ & $15,17 \pm 0,15 \mathrm{a}$ & 1,37 & 0,68 & 5,13 & 0,07 \\
\hline$\%$ Acidez (Ácido Láctico) & $0,39 \pm 0,08 \mathrm{a}$ & $0,43 \pm 0,05 \mathrm{a}$ & $0,34 \pm 0,01 \mathrm{a}$ & 0,01 & 0,01 & 1,49 & 0,33 \\
\hline pH & $5,85 \pm 0,03 \mathrm{a}$ & $4,74 \pm 0,03 \mathrm{~b}$ & $5,92 \pm 0,02 \mathrm{a}$ & 0,05 & 0,02 & 7,32 & 0,04 \\
\hline
\end{tabular}

Se presentó una ligera diferencia entre los valores de $\mathrm{pH}(p<0,05)$ en el Chicheme, siendo en el proveedor 2 , donde se observó los valores más bajos. En cuanto a la acidez, todos, estuvieron por encima de $0,14 \%$ establecido en las normas. Al analizar los valores de azúcares totales y reductores, se encontró que los proveedores estuvieron dentro de lo señalado en la normatividad. Los valores de azúcares reductores y azúcares totales en esta bebida fueron estadísticamente iguales en las muestras de las tres famiempresas, presentando los porcentajes mayores el proveedor 1. Estos resultados fueron similares a los hallados por Cervantes-Contreras y Pedroza-Rodríguez, (2007) quienes estudiaron el contenido de azúcares reductores en el pulque (bebida mexicana artesanal y fermentada) y encontraron valores de 4,0 y $4.75 \mathrm{~g} / \mathrm{L}$.

En la Tabla 5, se muestran los datos globales de la caracterización bromatológica y fisicoquímica de la Avena Sinuana y el Chicheme, es decir el promedio de los tres proveedores para cada producto. Se observaron porcentajes similares de humedad en ambos productos. En cuanto a las cenizas de la Avena Sinuana, se puede ver que fueron relativamente más altas. Similares a las reportadas por Muñoz-Insa et al., (2011) para malteada de avena líquida. Mientras que el porcentaje de humedad en la Avena Sinuana, varió con respecto a lo encontrado por Pagés et al., (2013).

En los valores de los porcentajes de azúcares totales y reductores, se resalta que no existe una norma donde se especifique la cantidad que deben tener los productos lácteos, por tanto, se toma como referencia la cantidad que posee la leche, los cuales varían de 3,5 a $4,1 \%$ (Decreto 616,2006 ). Por lo que se observa que ambos productos en todas las famiempresas, estuvieron dentro de lo establecido. Se observa que la cantidad de proteínas promedio global para el Chicheme, fue relativamente más alta, respecto a la Avena Sinuana, pero en general ambos cumplieron con la cantidad mínima requerida para este tipo de productos, la cual debe ser de $1.5 \%$ p/v (NTC 5246, 2004). Es importante destacar una gran diferencia de los productos en cuanto a los porcentajes de acidez, lo cual se explica por la fermentación que se produce en el Chicheme, debido a su elaboración con maíz. Los grados ${ }^{\circ}$ Brix de ambas bebidas estuvieron dentro de los parámetros establecidos, y fueron muy similares a los reportados por Quintero-Salazar et al., (2012), MuñizMárquez et al., (2013), Becerra et al., (2014).

\section{Caracterización microbiológica de la Avena Sinuana y del Chicheme}

La Tabla 6, esquematiza los resultados obtenidos en la caracterización microbiológica de la Avena Sinuana en UFC/mL de producto. Con base a lo exigido por las NTC 4458 (2007) y NTC 4779 (2007). Se observó en cuanto a los recuentos de mesófilos aerobios, que todos los proveedores en los días evaluados, estuvieron por encima de lo estipulado $\left(2,0 \log _{10} \mathrm{UFC} / \mathrm{mL}\right)$. Lo que pudo ser debido a un inadecuado ambiente de procesamiento en las famiempresas. Estos resultados fueron similares a los reportados por Pagés et al., (2013) quienes analizaron una bebida fortificada en polvo a base de avena y encontraron un alto recuento de mesófilos aerobios de $\left(2,1 \times 10^{3}\right)$. Así mismo con los hallados por Granados et al., (2010) quienes analizaron la calidad microbiológica de un producto lácteo y encontraron recuentos de aerobios mesófilos entre 3,7 y 4,4 Log $\log _{10} \mathrm{UFC/g}$. Lo cual atribuyeron a las condiciones donde se elaboraron dichos alimentos. 
Tabla 5: Caracterización bromatológica y fisicoquímica de la Avena Sinuana y el Chicheme

\begin{tabular}{|l|c|c|}
\hline \multirow{2}{*}{ Parámetro } & \multicolumn{2}{|c|}{ Promedios globales entre proveedores } \\
\cline { 2 - 3 } & Avena Sinuana & Chicheme \\
\hline$\%$ Humedad & $81,77 \pm 4,16$ & $83,26 \pm 0,90$ \\
\hline$\%$ Cenizas (BS) & $1,39 \pm 0,18$ & $0,94 \pm 0,10$ \\
\hline$\%$ Proteína & $5,36 \pm 0,95$ & $6,77 \pm 0,60$ \\
\hline$\%$ Grasa (BS) & $0,93 \pm 0,35$ & $1,02 \pm 0,30$ \\
\hline$\%$ Azúcares Totales & $5,03 \pm 0,62$ & $4,02 \pm 0,97$ \\
\hline$\%$ Azúcares Reductores & $5,51 \pm 1,22$ & $3,99 \pm 0,78$ \\
\hline ○Brix & $14,36 \pm 0,21$ & $15,39 \pm 0,50$ \\
\hline Acidez (\% Ácido Láctico) & $0,12 \pm 0,02$ & $0,39 \pm 0,05$ \\
\hline pH & $5,46 \pm 0,97$ & $5,50 \pm 0,66$ \\
\hline
\end{tabular}

Tabla 6: Caracterización microbiológica de la Avena Sinuana, valores expresados en $\log _{10}$ UFC/mL

\begin{tabular}{|c|c|c|c|c|c|c|c|c|c|}
\hline \multirow{3}{*}{$\begin{array}{c}\text { Proveedores } \\
\text { Parámetros/Días }\end{array}$} & \multicolumn{9}{|c|}{ Avena Sinuana } \\
\hline & \multicolumn{3}{|c|}{ Proveedor 1} & \multicolumn{3}{|c|}{ Proveedor 2} & \multicolumn{3}{|c|}{ Proveedor 3} \\
\hline & Día 1 & Día 2 & Día 3 & Día 1 & Día 2 & Día 3 & Día 1 & Día 2 & Día 3 \\
\hline Mesófilos & 3,08 & 3,04 & 3,36 & 4,40 & 4,34 & 4,38 & 3,20 & 3,34 & 3,20 \\
\hline Coliformes Totales & 3,38 & 3,38 & 3,38 & 3,38 & 3,38 & 3,38 & 3,38 & 3,38 & 3,38 \\
\hline Coliformes Fecales & 3,38 & 1,30 & 1,00 & 1,95 & 3,38 & 3,04 & 3,38 & 3,38 & 3,38 \\
\hline Bacterias Lácticas & 2,00 & 2,00 & 3,53 & 2,00 & 2,00 & 2,00 & 1,00 & 1,00 & 1,00 \\
\hline S. aureus & 2,00 & 2,00 & 3,23 & 2,00 & 3,76 & 3,23 & 2,00 & 2,00 & 2,00 \\
\hline
\end{tabular}

En los coliformes totales y fecales se observó que todos los proveedores sobrepasaron los límites de $(<1,0$ $\log _{10} \mathrm{UFC} / \mathrm{mL}$ ), permitidos por las normas, para este tipo de productos alimenticios. Lo que pudo ser debido a una contaminación posterior al proceso y a una deficiente manipulación del producto final. Estos resultados coinciden con los reportados por Montoya et al., (2014) quienes analizaron las características microbiológica de suero de leche y encontraron altos recuentos de coliformes totales $(5,5$ a 8,1 $\log _{10} \mathrm{UFC} \cdot \mathrm{mL}^{-1}$ ). Pero no con los hallados por Pua et al., (2011) quienes evaluaron las características microbiológicas de una bebida láctea enriquecida con calcio y vitamina $D$, e indicaron que los recuentos de coliformes totales, estuvieron dentro de lo establecido en el Decreto 616 (2006).

En cuanto a la presencia de coliformes fecales, los resultados de este trabajo, revelaron una contaminación directa en alguna etapa del proceso con una fuente de materia fecal, lo que representó un riesgo para la salud de los consumidores. Por tanto, es pertinente sugerir mayor higiene personal por parte de los manipuladores de dichos productos, así como mayor inspección de la materia prima para evitar la presencia de este estos microorganismos. Granados et al., (2012) encontraron altos recuentos de coliformes fecales en el suero costeño elaborado en los municipios de Turbaco, Arjona y Carmen de Bolívar, lo que atribuyeron a las deficientes condiciones higiénico-sanitarias en la elaboración de este producto en los municipios.

Las muestras de la Avena Sinuana, de los proveedores 1 y 2, indicaron alta contaminación con $s$. aureus, ya que se sobrepasaron los límites establecidos por la NTC 4779 (2007) la cual contempla un máximo de $(<1,0$ $\log _{10}$ UFC/mL). Según Pazmiño et al., (2014) los manipuladores de alimentos son la principal fuente de contaminación por cepas de s. aureus, el cual está presente en fosas nasales, garganta, cabello y/o piel, por lo que la presencia de este microorganismo indicaría un alto grado de contaminación por una deficiente manipulación durante su procesamiento. Se sugiere entone que los operadores sean personas sanas y conocedoras de los conceptos referentes a las Buenas Practicas de Manufacturas.

En la Tabla 7, se esquematizan los análisis de varianza realizados a los recuentos microbianos de la Avena Sinuana, se presentan los promedios de los tres días, por cada proveedor. Para facilitar el cálculo de los parámetros estadísticos y cumplir con los supuestos de normalidad, los datos fueron transformados a logaritmo en base 10. Se presentaron diferencias estadísticamente significativas entre los proveedores, en cuanto a los promedios de mesófilos $(p<0,05)$, siendo en el proveedor 2 , donde se observó el valor más alto. 
Así mismo se observó diferencias en cuanto a los recuentos de bacterias acido lácticas $(p<0,05)$, siendo más alto en las muestras del proveedor 1 . El promedio de $s$. aureus fue mayor en el proveedor $2(p<0,05)$ lo que estuvo muy por encima de lo establecido en la norma NTC 4779 (2007).

En cuanto a los recuentos de coliformes totales y fecales, no se observaron diferencias estadísticas entre los tres proveedores $(p>0,05)$, se resalta que todos sobrepasaron lo señalado en la normatividad para este tipo de productos (1,0 Log10 UFC/mL) NTC 4458 (2007).

Tabla 7: Análisis de varianza a los recuentos microbianos de Avena Sinuana, valores en $\log _{10} \mathrm{UFC} / \mathrm{mL}$

\begin{tabular}{|l|c|c|c|c|c|c|}
\hline \multicolumn{4}{|c|}{ Avena Sinuana } & \multicolumn{2}{c|}{ Análisis de varianza } \\
\hline Parámetros/Proveedor & Proveedor 1 & Proveedor 2 & Proveedor 3 & Total & Valor $F$ & $p$-valor \\
\hline Mesófilos & $3,15 \pm 0,19 \mathrm{a}$ & $4,37 \pm 0,03 \mathrm{~b}$ & $3,25 \pm 0,08 \mathrm{a}$ & $3,59 \pm 0,67$ & 6,97 & 0,04 \\
\hline Coliformes Totales & $3,38 \pm 0,00 \mathrm{a}$ & $3,38 \pm 0,00 \mathrm{a}$ & $3,38 \pm 0,00 \mathrm{a}$ & $3,38 \pm 0,00$ & 0,00 & 1,00 \\
\hline Coliformes Fecales & $2,09 \pm 0,85 \mathrm{a}$ & $2,77 \pm 0,75 \mathrm{a}$ & $3,38 \pm 0,00 \mathrm{a}$ & $2,75 \pm 0,64$ & 0,13 & 0,88 \\
\hline Bacterias Lácticas & $2,53 \pm 0,86 \mathrm{a}$ & $2,01 \pm 0,01 \mathrm{a}$ & $1,00 \pm 0,03 \mathrm{~b}$ & $1,85 \pm 0,77$ & 6,95 & 0,04 \\
\hline S. aureus & $2,41 \pm 0,71 \mathrm{a}$ & $3,66 \pm 1,46 \mathrm{~b}$ & $2,00 \pm 0,02 \mathrm{a}$ & $2,69 \pm 0,86$ & 8,11 & 0,03 \\
\hline
\end{tabular}

En la Tabla 8, se reportan los valores de los recuentos realizados a las muestras del Chicheme entre los proveedores. De acuerdo con lo establecido por las normas, se observó que todas sobrepasaron los límites señalados en las NTC 4458 (2004) y NTC 4779 (2007). Estos resultados indicaron baja calidad sanitaria de este producto y una deficiente manipulación durante el proceso de elaboración.

Tabla 8: Caracterización microbiológica del Chicheme, valores expresados en Log 10 UFC/mL

\begin{tabular}{|c|c|c|c|c|c|c|c|c|c|}
\hline \multirow{2}{*}{ Proveedores } & \multicolumn{9}{|c|}{ Chicheme } \\
\cline { 2 - 13 } & \multicolumn{3}{|c|}{ Proveedor 1 } & \multicolumn{3}{c|}{ Proveedor 2 } & \multicolumn{4}{c|}{ Proveedor 3 } \\
\hline Parámetros/Días & Día 1 & Día 2 & Día 3 & Día 1 & Día 2 & Día 3 & Día 1 & Día 2 & Día 3 \\
\hline Mesófilos & 3,36 & 4,45 & 4,38 & 4,30 & 3,48 & 3,23 & 3,00 & 3,34 & 3,32 \\
\hline Coliformes Totales & 3,38 & 3,38 & 3,38 & 3,38 & 3,38 & 1,64 & 3,38 & 2,70 & 3,32 \\
\hline Coliformes Fecales & 3,38 & 3,38 & 3,38 & 3,38 & 3,38 & 1,54 & 3,38 & 2,90 & 3,36 \\
\hline Bacterias Lácticas & 2,00 & 2,00 & 2,00 & 1,00 & 3,48 & 3,23 & 2,00 & 2,00 & 1,00 \\
\hline S. aureus & 3,30 & 2,00 & 2,00 & 5,15 & 2,00 & 2,00 & 2,48 & 3,54 & 2,00 \\
\hline
\end{tabular}

Según Ocampo et al., (2012) un recuento bajo de aerobios mesófilos no implica necesariamente la ausencia de patógenos o sus toxinas, de la misma manera que un recuento elevado no significa presencia de microbiota patógena. Con respecto, a los resultados obtenidos de coliformes totales y fecales, se observó que todas las muestras evaluadas en los tres días, excedieron los límites permitidos, lo que representó un riesgo para la salud de los consumidores. Granados et al., (2012) y Montoya et al., (2014) señalan que la presencia de estos microorganismos es indicativo de incorrectas prácticas durante la manufactura, baja calidad del producto y posible contaminación de la materia prima. Pazmiño et al., (2014) en relación a los recuentos microbiológicos en la chicha de arroz una bebida tradicional de Ecuador, obtuvieron en promedio valores de 2.7 y $2.5 \log _{10} \mathrm{UFC} / \mathrm{mL}$ de coliformes totales. En la Tabla 9, se muestran los análisis de varianza realizados a los recuentos microbianos de los tres proveedores del Chicheme. No se observaron diferencias estadísticamente significativas, en cuanto a los mesófilos, y coliformes $(p>0,05)$.

Al analizar los datos del recuento de bacterias lácticas, se encontró que el Chicheme procedente del proveedor 2, presentó los resultados más altos y estadísticamente diferentes a los demás $(p<0,05)$. Es conocido que este tipo de microorganismos no son patógenos, pero su acción desencadena un proceso donde la lactosa (azúcar de la leche) se transforma en ácido láctico, por lo que si no se controlan los niveles, pueden llegar alterar las características organoléptica de los productos alimenticios (QuinteroSalazar et al., 2012; Luana et al., 2014). 
Tabla 9: Análisis de varianza a los recuentos microbiológicos del Chicheme. Valores en $\log _{10}$ UFC/mL

\begin{tabular}{|c|c|c|c|c|c|c|}
\hline \multicolumn{5}{|c|}{ Chicheme } & \multicolumn{2}{|c|}{ Análisis de varianza } \\
\hline Parámetros/Proveedores & Proveedor 1 & Proveedor 2 & Proveedor 3 & Total & Valor F & $p$-valor \\
\hline Mesófilos & $4,26 \pm 0,61 a$ & $4,12 \pm 0,46 a$ & $4,25 \pm 0,19 a$ & $4,21 \pm 0,08$ & 2,65 & 0,18 \\
\hline Coliformes Totales & $3,38 \pm 0,00 a$ & $3,21 \pm 1,00 a$ & $3,25 \pm 0,39 a$ & $3,28 \pm 0,09$ & 1,98 & 0,25 \\
\hline Coliformes Fecales & $3,38 \pm 0,00 a$ & $3,19 \pm 1,05 a$ & $3,26 \pm 0,27 a$ & $3,28 \pm 0,10$ & 2,02 & 0,25 \\
\hline Bacterias Lácticas & $2,01 \pm 0,01 a$ & $3,20 \pm 1,36 b$ & $1,85 \pm 0,58 a$ & $2,35 \pm 0,74$ & 13,07 & 0,04 \\
\hline S. aureus & $2,87 \pm 0,75 a$ & $2,73 \pm 0,66 a$ & $3,11 \pm 0,79 b$ & $2,90 \pm 0,19$ & 6,98 & 0,05 \\
\hline
\end{tabular}

Gupta et al., (2010) señalaron que en este tipo de bebidas, la fermentación del ácido láctico lleva a un descenso del $\mathrm{pH}$, lo que ocasiona un efecto bacteriostático, a la vez que las características organolépticas del producto se modifican tales como el sabor, el olor, entre otras. Las muestras de Chicheme de maíz evaluadas de los tres proveedores presentaron recuentos de bacterias lácticas por encima de lo establecido en las normas técnicas (2,0 $\log _{10} \mathrm{UFC} / \mathrm{mL}$ ), a pesar del corto periodo de estudio (3 días). Lo cual fue similar a lo reportado por Pazmiño et al., (2014) quienes obtuvieron diferencias estadísticamente significativas entre productores de chicha de arroz, para los recuentos de las bacterias ácido-lácticas, lo cual atribuyeron a los distintos tiempos de fermentación. Para bacterias ácido lácticas Gassem (2002), (citado por Pazmiño et al., 2014), por reportó en un estudio realizado en una bebida de trigo y malta denominada Sobia, originaria de Arabia Saudita, valores de 4.10 a $8.19 \mathrm{log}$ UFC/mL. En el trabajo realizado por Sánchez et al. (2010) el Axokot una bebida fermentada tradicional de origen mexicano presentó 2,91 log UFC/ml de bacterias ácido lácticas. La presencia de estas bacterias podría atribuirse a la falta de precaución en la elaboración de la bebida (García et al., 2010).

En general los porcentajes más altos de microorganismos para el Chicheme estuvieron en el proveedor 2. Aunque se resalta que todos sobrepasaron los límites señalados en las normas, lo que revela la falta de tecnificación de los procesos de elaboración en las famiempresas que se visitaron. Estos resultados fueron similares a los encontrados por Cristóbal-Delgado y Maurtua-Torres, (2003) en su estudio sobre un producto lácteo fresco y artesanal comercializados en Perú, donde encontraron que la carga microbiana del 97,4\% de las muestras analizadas, estuvieron por encima de los valores máximos permitidos por las Normas Técnicas Peruanas para los diferentes grupos de microorganismos, lo cual fue atribuido a las deficiencias sanitarias durante la manipulación. Igualmente los datos hallados en este trabajo, coinciden con los reportados por Granados et al., (2010) quienes analizaron un producto lácteo artesanal, y encontraron recuentos microbianos por encima de lo recomendado por las Normas Técnicas Colombianas. Así mismo también con los reportados por Arroyo et al., (2011) (citado por Pazmiño et al., 2014) quienes encontraron altos recuentos de aerobios mesófilos, Coliformes totales, y s. aureus, en su estudio del perfil microbiológico de la chicha de arroz de Venezuela. Estos autores ratificaron que es indispensable controlar estos parámetros en las bebidas de tipo artesanal, pues están directamente relacionados con la calidad y aceptación por parte de los consumidores.

\section{CONCLUSIONES}

Las muestras de Avena Sinuana y Chicheme de las famiempresas escogidas de los municipios de Cereté y Cienaga de Oro Córdoba, cumplieron con los parámetros de humedad, proteínas; mientras que los porcentajes de grasa en la Avena Sinuana y de cenizas en el Chicheme estuvieron por debajo de lo exigido en las normas. Los análisis fisicoquímicos indicaron que las muestras de los productos se hallaron dentro de lo establecido, mostrando Avena Sinuana algunas diferencias entre proveedores en los azúcares totales, $\mathrm{pH}$, y acidez, $(p<0,05)$, mientras los azúcares reductores y ${ }^{\circ}$ Brix fueron estadísticamente iguales. Por su parte en el Chicheme no hubo diferencias significativas $(p>0,05)$ entre los azúcares totales, reductores, oBrix, acidez; y los valores de $\mathrm{pH}$ fueron estadísticamente diferentes $(p<0,05)$. Los análisis microbiológicos indicaron que todos los recuentos de mesófilos, coliformes totales, coliformes fecales, bacterias lácticas, Staphylococcus aureus, en ambas bebidas excedieron los límites básicos fijados en las normatividades colombianas vigentes para este tipo de productos. Lo cual reveló que estas son bebidas, con una cantidad adecuada de nutrientes, y elaboradas con deficientes condiciones higiénico-sanitarias.

\section{REFERENCIAS}

AOAC, Official Methods of Analysis of Official Analytical Chemists. 15th. Pub. by the A.O.A.C. Washington D.C. $(1990)$ 
Arzeno, M., y C. Troncoso, Alimentos tradicionales andinos, turismo y lugar: definiendo la nueva geografía de la Quebrada de Humahuaca (Argentina), Revista de Geografía Norte Grande, (52), 71-90 (2012)

Becerra, M. Bebidas Fermentadas a Partir de Maíz y Arroz: Elaboración, Control y Conservación. Alimentos Hoy, 22(31), 96-103 (2014)

Blanco, J. E., Gómez, D. M. C., \& Godoy, S. A. S. Alimentos tradicionales en Sonora, México: factores que influyen en su consumo. Innovar: revista de ciencias administrativas y sociales, 24(53), 127-139. (2014)

Cervantes-Contreras, R. y A. Pedroza-Rodríguez, El pulque bebida mexicana artesanal prehispánica: características microbiológicas y contenido alcohólico mediante espectroscopia, Publicación Científica en Ciencias Biomédicas: 5(8) 101-212 (2007)

Cristóbal-Delgado, R. y D. Maurtua-Torres, Evaluación bacteriológica de quesos frescos artesanales comercializados en Lima, Perú, y la supuesta acción bactericida de Lactobacillus spp. Revista Panameña de Salud Pública: 14(3), 158-164 (2003)

Decreto 616, Ministerio de Protección Social (Colombia), Reglamento técnico sobre los requisitos que debe cumplir la leche para consumo humano que se obtenga, procese, envase, transporte, comercialice, expenda, importe o exporte en el país, Diario Oficial de Colombia, 46-196 Bogotá, Colombia (2006)

Domínguez-López, A., A. Villanueva-Carvajal., C. Arriaga-Jordán y A. Espinoza-Ortega, Alimentos artesanales y tradicionales: el queso Oaxaca como un caso de estudio del centro de México, Estudios sociales (Hermosillo, Son.): 19(38), 165-193 (2011)

Dubois, M., y cuatro autores, Colorimetric Method for the Determination of Sugars and Related Substances, Division Biochemistry, Annals of Chemistry: 28(3), 350-356 (1956)

García, A. y E. Pacheco, Evaluación de una bebida láctea instantánea a base de harina de arracacha (Arracacha xanthorriza) con la adición de ácido fólico, Revista chilena de nutrición: 37(4), 480-492 (2010)

García, C., G. Arrázola y A. Durango, Producción de ácido láctico por vía biotecnológica, Temas agrarios: 15(2)9-26(2010)

Granados, C., G. Urbina y D. Acevedo, Tecnificación, caracterización fisicoquímica y microbiológica el queso de capa de Mompox Colombia, Biotecnología en el sector agropecuario y agroindustrial, 8(2), 41-45 (2010)

Granados, C., D. Acevedo y R. Torres, Calidad de la leche y del suero costeño de los municipios Turbaco, Arjona y Carmen de Bolívar - Colombia, Revista Lasallista de Investigación: 9(2), 132-137 (2012)

Gupta, S., S. Cox y N. Abu-Ghannam, N Process Optimization for the Development of a Functional Beverage Based on Lactic Acid Fermentation of Oats, Biochemical Engineering Journal, 52 (2), 199-204 (2010)

López-Arboleda, W., M. Ramírez-Castrillón., L. Mambuscay-Mena., y E. Osorio-Cadavid, Diversidad de levaduras asociadas a chichas tradicionales de Colombia. Revista Colombiana Biotecnología: 12(2), 176$186(2010)$

Luana, N. y otros cinco autores, Manufacture and characterization of a yogurt-like beverage made with oat flakes fermented by selected lactic acid bacteria, Int. J. Food Microbiology: 185 (1), 17-26 (2014)

Miller G. Use of dinitrosalicílic acid reagent for determination of reducing sugar, Annals of Chemistry: 426428 (1958)

Montoya, P. y otros cinco autores, Características fisicoquímica y microbiológica de suero de leche de queso Chihuahua, Investigación y Ciencia: 22(62), 11-16 (2014)

Muñiz-Márquez, D. y otros cuatro autores, Producción Artesanal del Aguamiel: Una Bebida Tradicional Mexicana, Revista Científica, 5(10), 12-19, (2013)

Muñoz-Insa, A., M. Gostl., M. Zarnkow y T. Becker, Optimization of the malting process of oat (Avena Sativa L.) as a raw material for fermented beverages, Spanish Journal of Agriculture Research: 9(2), 510-523 (2011)

NTC 2160, Norma Técnica Colombiana. Productos de molinería. Harina de avena cocida para consumo humano. Instituto Colombiano de Normas Técnicas y Certificación (ICONTEC), Bogotá, 10p (2006) 
NTC 4458. Norma Técnica Colombiana. Microbiología de alimentos. Instituto Colombiano de Normas Técnicas y Certificación (ICONTEC), Bogotá, 12p (2007)

NTC 4722, Normas Técnica Colombiana. Leche y productos lácteos. Método para determinar el contenido de grasa Método gravimétrico. Instituto Colombiano de Normas Técnicas y Certificación (ICONTEC), Bogotá, 23p (1999).

NTC 4779. Norma Técnica Colombiana. Microbiología de alimentos. Instituto Colombiano de Normas Técnicas y Certificación (ICONTEC), Bogotá, 25p (2007)

NTC 5246, Norma Técnica Colombiana Productos Lácteos, Bebida Láctea con Avena. Instituto Colombiano de Normas Técnicas y Certificación (ICONTEC), Bogotá, 10p (2004)

Ocampo, R. D., L.G. Zapateiro., J.M. Torres, Caracterización bromatológica, fisicoquímica, microbiológica y reológica de la pulpa de borojó (Borojó Patinoi Cuatrec), Revista Ciencia y Tecnología: 5 (1), 17-24 (2012)

Pagés, M., M. Zurita-Calderón y M. Mata, Diseño y elaboración de una bebida fortificada en polvo a base de avena y proteína aislada de soya destinada a una población de adultos mayores, Tesis de Gado en Ingeniería de Alimentos, Escuela Superior Politécnica del Litoral: ESPOL, Guayaquil-Ecuador (2013)

Pastrana, E., Evaluación de sustancias antimicrobianas naturales en la conservación de bebidas autóctonas del departamento de córdoba, Tesis de Maestría, Facultada de Ingeniería, 172p, Córdoba, Colombia (2013)

Pazmiño, D., M. Escudero, y N. Grijalva, Diversidad microbiana asociada a la chicha de arroz: una bebida tradicional de Bolívar-Ecuador, Enfoque UTE, 5(3), 1-6 (2014)

Pua, A., L. Caballer y E. Rivera, Evaluación de las características químicas, físicas y microbiológicas de una bebida láctea enriquecida, @ limentech: Ciencia y Tecnología Alimentaria: 9(1), 5-13 (2011)

Quintero-Salazar, B. y cuatro autores más, Consumo y conocimiento actual de una bebida fermentada tradicional en Ixtapan del Oro, México: la sambumbua, Revista Alteridades: 22(44), 115-129 (2012)

Rojas, P. Desarrollo y caracterización de una nueva bebida de avena, Tesis de Máster de Calidad, Desarrollo e Innovación de alimentos. Escuela Técnica Superior de Ingenierías Agrarias, Univ. de Valladolid, España (2012)

Sánchez, M.G. y seis autores, estudio preliminar del Axokot, bebida tradicional fermentada, bajo una perspectiva trans-disciplinaria, Investigación Universitaria Multidisciplinaria: 9(9), 113-124 (2010) 